\title{
Environmental Enrichment Ameliorates Behavioral Impairments Modeling Schizophrenia in Mice Lacking Metabotropic Glutamate Receptor 5
}

\author{
Emma L Burrows', Caitlin E McOmish ${ }^{1,2}$, Laetitia S Buret' ${ }^{1,3}$, Maarten Van den Buuse ${ }^{1,3}$ and \\ Anthony J Hannan ${ }^{*, 1,4}$ \\ IFlorey Institute of Neuroscience and Mental Health, Melbourne Brain Centre, University of Melbourne, Parkville, VIC, Australia; \\ ${ }^{2}$ Department of Psychiatry, The Sackler Institute for Developmental Psychobiology, Columbia University, NY, USA; ${ }^{3}$ School of Psychological Science, \\ La Trobe University, Bundoora, VIC, Australia; ${ }^{4}$ Department of Anatomy and Neuroscience, University of Melbourne, Parkville, VIC, Australia
}

\begin{abstract}
Schizophrenia arises from a complex interplay between genetic and environmental factors. Abnormalities in glutamatergic signaling have been proposed to underlie the emergence of symptoms, in light of various lines of evidence, including the psychotomimetic effects of NMDA receptor antagonists. Metabotropic glutamate receptor 5 ( $\mathrm{mGlu} 5$ ) has also been implicated in the disorder, and has been shown to physically interact with NMDA receptors. To clarify the role of mGlu5-dependent behavioral expression by environmental factors, we assessed mGlu5 knockout (KO) mice after exposure to environmental enrichment (EE) or reared under standard conditions. The mGlu5 $\mathrm{KO}$ mice showed reduced prepulse inhibition (PPI), long-term memory deficits, and spontaneous locomotor hyperactivity, which were all attenuated by EE. Examining the cellular impact of genetic and environmental manipulation, we show that EE significantly increased pyramidal cell dendritic branching and BDNF protein levels in the hippocampus of wild-type mice; however, mGlu5 KO mice were resistant to these alterations, suggesting that $\mathrm{mGlu} 5$ is critical to these responses. A selective effect of EE on the behavioral response to the NMDA receptor antagonist MK-80I in mGlu5 $\mathrm{KO}$ mice was seen. MK-80 I-induced hyperlocomotion was further potentiated in enriched mGlu5 KO mice and treatment with MK-80I reinstated PPI disruption in EE mGlu5 KO mice only, a response that is absent under standard housing conditions. Together, these results demonstrate an important role for mGlu5 in environmental modulation of schizophreniarelated behavioral impairments. Furthermore, this role of the mGlu5 receptor is mediated by interaction with NMDA receptor function, which may inform development of novel therapeutics.

Neuropsychopharmacology (2015) 40, 1947-1956; doi:I0.1038/npp.2015.44; published online 4 March 2015
\end{abstract}

\section{INTRODUCTION}

Gene-environment interactions are thought to have a role in the etiology of schizophrenia. While much progress has been made in recent years in understanding how genetic factors and other molecular mediators contribute to schizophrenia, less is known about how environmental factors interact with genetic predisposition and how the resulting alterations modulate pathogenesis and disease progression. The incorporation of environment as a factor in animal models of psychiatric disorders is providing a clearer picture of how genes and environment converge to produce and protect against aberrant behavioral phenotypes (Burrows et al, 2011).

The glutamatergic system has been widely implicated in the development of psychiatric illnesses, including schizophrenia.

\footnotetext{
*Correspondence: Professor AJ Hannan, Florey Institute of Neuroscience and Mental Health, Melbourne Brain Centre, University of Melbourne, Parkville, VIC 30 I0, Australia, Tel: +6I 39035 6638, Fax: +6I 39348 1707, E-mail: anthony.hannan@florey.edu.au

Received 15 September 2014; revised 21 January 2015; accepted 26 January 2015; accepted article preview online 10 February 2015
}

Support for the glutamatergic hypothesis of schizophrenia arises from observations that NMDA receptor (NMDAR) antagonists such as MK-801, phencyclidine (PCP), and ketamine induce psychosis-like symptoms in healthy subjects and exacerbate existing psychoses in schizophrenia patients (Krystal et al, 1994; Adler et al, 1999). Additional evidence lies in genetic linkage, neuroimaging, and post-mortem studies that have shown alterations in NMDA and metabotropic glutamate receptor expression (Meador-Woodruff and Healy, 2000; Mirnics et al, 2000; Devon et al, 2001; Gupta et al, 2005; van Elst et al, 2005). Furthermore, antipsychotic potential has been reported for compounds restoring glutamatergic dysfunction in animal models (Mohn et al, 1999; Fradley et al, 2005; Gray et al, 2009).

Importantly, functional and physical interactions have been identified between NMDAR and mGlu5 (Tu et al, 1999) indicating that these two glutamate receptors may operate in concert to mediate behavioral impairments of relevance to schizophrenia. For example, treatment with the mGlu5 antagonists, MPEP and MTEP, augments the hyperlocomotive effects of PCP and MK-801 (Henry et al, 2002; Campbell 
et al, 2004; Pietraszek et al, 2005) while mGlu5 knockout (KO) mice show baseline hyperactivity and a hypersensitivity to MK-801-induced hyperlocomotion (Lipina et al, 2007; Gray et al, 2009). mGlu5 KO mice also demonstrate impaired PPI (Kinney et al, 2003; Brody et al, 2004) and the amelioration of this deficit by chronic administration of clozapine is accompanied by an increase in NMDAR binding (Gray et al, 2009). Acute mGlu5 antagonism potentiates PPI disruption by NMDAR antagonists (Kinney et al, 2003; Brody and Geyer, 2004; Pietraszek et al, 2005), and mGlu5 KO mice show reduced sensitivity to MK-801induced PPI disruptions (Lipina et al, 2007). Further evidence of NMDAR dysfunction in mGlu5 $\mathrm{KO}$ mice has been suggested by the loss of NMDAR-mediated components of hippocampal CA1 LTP (Lu et al, 1997; Jia et al, 1998). Accordingly, mGlu5 KO mice show memory impairments (Lu et al, 1997; Rodrigues et al, 2002; Gray et al, 2009) that depend on NMDAR-mediated plasticity in the CA1 region of the hippocampus (Tsien et al, 1996). Allosteric modulators of mGlu5 have been developed with a view to target this receptor, therapeutically; however, the exact role of mGlu5 in schizophrenia endophenotypes remains unclear. While significant progress has been made in establishing the importance of mGlu5 in behavioral regulation using knockout mice, understanding how this receptor produces these phenotypes within the complex framework of gene-byenvironment interactions known to be associated with these illnesses is critical to understand how it may be contributing to schizophrenia, and its potential role as a therapeutic target (Gray and Hannan, 2007; Burrows et al, 2011).

Environmental enrichment (EE), a paradigm that induces experience-dependent plasticity via enhanced cognitive, sensory, and motor stimulation, can lead to a variety of molecular, cellular, and behavioral changes, including enhancing learning, memory, and synaptic plasticity, both in wild-type mice and in animal models of CNS disorders (Nithianantharajah and Hannan, 2006). Notably, this form of environmental modification has been demonstrated to ameliorate behavioral abnormalities in rodent models of psychiatric disorders, including schizophrenia-like behaviors (Brenes et al, 2008; Chourbaji et al, 2008; McOmish et al, 2008). EE has been shown to upregulate expression of NMDAR subunits, as well as other components of the glutamatergic system (Tang et al, 2001; Bredy et al, 2003; Naka et al, 2005; Andin et al, 2007; Mora et al, 2007) suggesting that disruptions resulting from NMDAR dysfunction could be ameliorated following exposure to enriched housing. However, it is not clear whether EE influences the behavioral consequences of mGlu5 deficiency and what the role of NMDAR in these changes is. Therefore, the aim of the present study was to investigate the effects of EE upon behavioral endophenotypes with relevance to schizophrenia in mice lacking mGlu5.

\section{MATERIALS AND METHODS}

\section{Animals and Housing}

The mGlu5 knockout (KO) mouse line (Grm5tm1Rod) was obtained from Jackson Laboratories (Bar Harbor, Maine; Lu et al, 1997). All mice were on a C57Bl/6 background and $\mathrm{KO}$ and WT animals were generated from heterozygous breeding pairs. Genotypes were determined by PCR, from a tail biopsy. Mice were weaned at 4 weeks postnatal and housed 4 per cage, randomly assigned to one of two conditions with food and water ad libitum: standard-housed (SH) or environmentally enriched (EE). SH mice were housed in open top standard mouse cages $(34 \times 16 \times 16 \mathrm{~cm})$ with basic nesting materials. EE animals were housed in larger cages $(40 \times 28 \times 18 \mathrm{~cm})$ containing a variety of novel stimuli (cardboard, wooden objects, tunnels, nesting material), changed once per week and with access to running wheels. EE mice were additionally exposed to a larger exploratory chamber (1001 volume) with differing configurations of platforms, bridges, ropes, and stimuli for $1 \mathrm{~h} /$ day, 5 days a week. Four weeks of post-weaning EE were completed before behavioral testing began. The holding room was maintained on a $12: 12 \mathrm{~h}$ light/dark cycle, at $20 \pm 1{ }^{\circ} \mathrm{C}$. Neither sex effects nor litter effects were detected, so data were pooled. Behavioral testing was conducted in the light period. Testing was performed blind to genotype and all procedures were approved by the Institutional Animal Ethics Committee.

\section{Behavioral Testing}

Sequence of behavioral testing. MK-801-induced hyperlocomotion (8-9 weeks of age) and disruptions in PPI (1114 weeks of age) were tested in one cohort. Separate cohorts were assessed for cognitive function (Y-maze at 8 weeks of age and Morris water maze (MWM) at 9 weeks of age) and anxiety on the light-dark test ( 8 weeks of age) and elevated plus maze (9 weeks of age). One week was given between behavioral tests.

Locomotor activity. Photo-beam arenas were used to monitor distance moved. Mice were habituated to the testing apparatus for $15 \mathrm{~min}$ over 4 consecutive days before MK-801 testing to allow $\mathrm{KO}$ and WT mice to reach a comparable baseline. For MK-801 (Sigma-Aldrich, in 0.9\% saline) sensitivity testing, after $30 \mathrm{~min}$ of exploration mice were injected intraperitoneally (i.p.) with saline, 0.15 or $0.25 \mathrm{mg} / \mathrm{kg}$ doses and exploratory activity was analyzed for a further $60 \mathrm{~min}$.

Prepulse inhibition and acoustic startle response. Prepulse inhibition (PPI) was measured as previously described (van den Buuse et al, 2005; van den Buuse et al, 2011) using automated SR Lab startle equipment (San Diego Instruments, San Diego, CA). For drug treatment experiments, mice were injected with MK-801 or saline $15 \mathrm{~min}$ before being placed in the chambers. Acoustic stimuli were delivered over a 70- $\mathrm{dB}$ background noise through ceilingmounted speakers. Each session consisted of 104 trials where the first and last eight trials consisted of 'pulse only' stimuli of $115 \mathrm{~dB}$ lasting $40 \mathrm{~ms}$ (P115 trials, Blocks 1 and 4, respectively). The middle 88 pulses consisted of a random delivery of 16 P115 trials (startle only, Blocks 2 and 3), 8 nostimulus trials, and 64 prepulse trials, consisting of a $20-\mathrm{ms}$ stimulus $2,4,8$, or $16 \mathrm{~dB}$ above $70 \mathrm{~dB}$ background 30 or $100 \mathrm{~ms}$ before a $115-\mathrm{dB}$ startling pulse. Trials were presented with variable intervals (10-37 s). PPI was calculated as the difference between median startle responses (median of all pulse only trials) to the pulse-alone trials and the 
prepulse-pulse trials, divided by the response to the pulsealone trial $\times 100 \%$. All mice regardless of treatment or group showed increasing PPI with each level of prepulse intensity so data were analyzed as average PPI (data not shown; main effect of prepulse: $\left.\mathrm{F}_{2,88}=9.38, p<0.001\right)$.

Y-maze. Three different visual intramaze cues were placed on the end wall of each arm of a grey Plexiglas Y-maze $(30 \times 10 \times 17 \mathrm{~cm}$ per arm). Mice were placed into a randomly assigned arm of the maze (home arm) and allowed to explore the maze (home and familiar arm) with one of the arms (novel arm) closed for $10 \mathrm{~min}$ (training trial). After a 1-h inter-trial interval, mice were returned to the same starting arm, with access to all three arms for 5 min (test trial). Data were scored using the Noldus Ethovision (v3; Wageningen, The Netherlands) automated tracking system. Mice were excluded from analysis if they possessed low exploratory activity in either the training or test trial, defined as fewer than 18 total arm entries, or showed a preference for one arm in the training trial.

Morris water maze. MWM was performed in a dark-green circular tank $(144 \mathrm{~cm})$, filled with water made opaque with non-toxic paint and maintained at a constant $25 \pm 1{ }^{\circ} \mathrm{C}$ temperature. Large cues visible from the tank were placed on the walls and around the room. Mice were habituated to the water and the presence of a submerged platform with three preliminary trials. Mice were trained to find a submerged platform for four 90-s trials per day on 9 consecutive days and tested for recall in a single probe trial on the 10th day when the platform was unavailable. Before assessing learning, two visible platform trials (during which a flag was placed on the platform) were conducted to assess visual acuity. Data were scored using the Noldus Ethovision (v3; Wageningen) automated tracking system. For analysis, the tank was divided into four quadrants (platform, opposite platform, left, and right). The platform location varied between mice to avoid quadrant bias, and starting positions were randomized. In addition to latency, area under the learning acquisition curve (area under curve: AUC) was calculated for each animal (Youngblood et al, 1997; Terry and Mahadik, 2007).

Elevated-plus maze. The elevated-plus maze consisted of two open $(25 \mathrm{~cm} \times 8 \mathrm{~cm} \times 0.5 \mathrm{~cm})$ and two closed $(25 \mathrm{~cm} \times 8$ $\mathrm{cm} \times 20 \mathrm{~cm}$ ) arms emanating from a common central platform $(8 \mathrm{~cm} \times 8 \mathrm{~cm})$ to form a plus shape and was elevated to $80 \mathrm{~cm}$ above floor level. Mice were habituated to the testing room for $1 \mathrm{~h}$ and then placed onto the central platform facing an open arm for a 6-min trial. The maze was thoroughly cleaned using $70 \%$ ethanol between subjects and scoring was performed using the Noldus Ethovision automated tracking system (version 3).

Light-dark box. Photo beam arenas (E63-10, TruScan, Coulbourn Instruments, Allentown, PA) with a light-dark box insert placed over half the arena were used to monitor the exploratory activity of mice. Animals were placed in the light area facing entry into the dark area and allowed to enter. The light $(750 \mathrm{~lx})$ was then switched on and the 10-min trial started.

\section{Assessment of BDNF Protein Levels by ELISA}

Mice were killed by cervical dislocation, hippocampi (right) were rapidly dissected, snap frozen on dry ice and stored at $-80^{\circ} \mathrm{C}$. Frozen tissue samples were sonicated in lysis buffer containing $100 \mathrm{mM}$ Tris- $\mathrm{HCl} \mathrm{pH} 7.0,2 \%$ bovine serum albumin (BSA), $1 \mathrm{M} \mathrm{NaCl}, 4 \mathrm{mM}$ EDTA, $2 \%$ Triton X-100 and the Complete Protease inhibitor cocktail (Roche, Castle Hill, NSW, Australia). Extracts were centrifuged for $30 \mathrm{~min}$ at $14000 \mathrm{~g}$ at $4{ }^{\circ} \mathrm{C}$, the supernatant isolated and protein concentrations determined using a Bradford assay (Bio-Rad, Hercules, CA). Samples were plated at equivalent concentrations for each brain region. The E-max BDNF ELISA kit (Promega, Madison, WI) was used to measure total BDNF levels, which were expressed as a proportion of the mean standard-housed WT control BDNF levels.

\section{Measurement of Dendritic Complexity in CA1 Pyramidal Cells}

Fresh hemidissected brains (left) were processed using the FD Rapid GolgiStain kit (FD NeuroTechnologies) according to the manufacturer's instructions. Five Golgi-impregnated pyramidal neurons from the hippocampus (defined as being between Bregma -1.58 and -3.5 of Paxinos and Franklin, 2001), from 3 different sections, to give a total of 25 cells analyzed per animal, were traced in their entirety using Neurolucida software (MicroBrightField, Williston). To examine dendritic branching and complexity, Sholl analysis (Sholl, 1953) was performed using NeuroExplorer software (MicroBrightField, Vermont).

\section{NMDAR Subunit Quantification by Western Blot}

Samples were lysed in RIPA buffer (50 mM Tris pH 8.0, 0.1\% SDS, $1 \%$ Triton X-100, $150 \mathrm{mM}$ sodium chloride, $\mathrm{dH}_{2} \mathrm{O}$, phosphatase inhibitor $(1: 50)$ and protease inhibitor $(1: 200))$, sonicated and then centrifuged for $18 \mathrm{~min}$ at $13000 \mathrm{~g}$ at $4^{\circ} \mathrm{C}$. In all, $50 \mu \mathrm{g}$ of protein was resolved by SDS-polyacrylamide gel ( $8 \%$ acrylamide gels) and transferred onto nitrocellulose membranes. Membranes were blocked for $2 \mathrm{~h}$ at room temperature in TBST $(20 \mathrm{mM}$ Tris, $150 \mathrm{mM}$ sodium chloride, $0.1 \%$ TWEEN-20, $\mathrm{dH}_{2} \mathrm{O}$ ) with $5 \%$ non-fat milk. Membranes were incubated in primary antibody in TBST, 5\%BSA overnight at $4{ }^{\circ} \mathrm{C}$, anti-NMDAR2C $(1: 500$; ab110, Abcam, Cambridge, UK; which also detects GluN2A, GluN2B, and GluN1), or anti-NMDAR2A (1:2000; ab14596, Abcam). Membranes were then washed $3 \times$ for $10 \mathrm{~min}$ in TBS-T and incubated in HRP-linked secondary antibody for $1 \mathrm{~h} 30 \mathrm{~min}$ at room temperature (Cell Signaling Technology). HRP was visualized using LumiGLO Reagent (Cell Signaling, Danvers, MA) and Ultra Western Lightning Ultra (Perkin-Elmer) and images were captured using a Luminescence Image Analyzer (LAS-4000; FujiFilm Life Science, Stamford, CT) and analyzed using Image Quant software (GE Healthcare, Baulkham Hills, NSW, Australia). Outliers were removed when they fell outside $2 \times$ the standard deviation.

\section{Statistical Analysis}

All data are expressed as mean \pm standard error of the mean (SEM). Groups were compared by three-way ANOVA with repeated measures where appropriate, using SPSS. Between- 
group factors were genotype and environment. Within group, repeated-measures factors were treatment (drug vs saline treatment), time (for locomotor activity), prepulse intensity, ISI interval, startle block (for PPI experiments), and distance from the soma (for dendritic analysis). Bonferroni-corrected pair-wise comparisons were conducted when main effects were significant. Neither sex effects nor litter effects were detected, so data were pooled. Significance was accepted at $p<0.05$.

\section{RESULTS}

\section{Environmental Enrichment Modulates Baseline Hyperactivity in mGlu5 KO Mice}

SH KO mice were initially hyperactive compared with WT; however, activity normalized by the third day of habituation (Figure 1; genotype: $\mathrm{F}_{1,47}=5.57, p<0.05$; genotype $\times$ day interaction: $\mathrm{F}_{3,143}=6.29, p<0.01$; days 1 and $2 \mathrm{WT}$ vs $\mathrm{KO}$, $p<0.05)$. EE reduced locomotor activity in both WT and KO animals during the 4 days of habituation (environment: $\left.\mathrm{F}_{1,47}=13.05, p<0.001\right)$.

\section{Environmental Enrichment Restores Spatial Learning in the MWM but not Y-Maze}

Over the 9 days of trials with a hidden platform, mGlu5 $\mathrm{KO}$ mice consistently showed longer escape latencies compared with WT mice (Figure 2a; genotype: $\mathrm{F}_{1,41}=26.55, p<0.001$ ). Impaired learning in $\mathrm{SH} \mathrm{KO}$ mice was also reflected by significantly higher AUC latencies compared with standardhoused WT controls (Figure 2b; genotype: $\mathrm{F}_{1,43}=38.99$, $p<0.001)$. EE significantly enhanced ability to locate the hidden platform, with enriched mice exhibiting much quicker escape latencies compared with standard housed controls (Figure 2a; environment: $\mathrm{F}_{1,41}=24.33, p<0.001$ ). EE significantly decreased AUC latencies in KO mice compared with KO mice housed under standard conditions, but there was no such effect in WT mice (Figure 2b; gene $\times$ environment interaction: $\mathrm{F}_{1,43}=7.94, p<0.01$; KOSH $v$ s KOEE $p<0.05$ ).

When tested for memory of the position of the platform, $\mathrm{SH}$ KO mice did not recall the location of the platform, showing no preference for any quadrant (Figure 2c). EE improved memory recall in $\mathrm{KO}$ mice, evidenced by a clear preference for the target quadrant compared with the other quadrants (Figure 2c; KOEE: $\mathrm{F}_{3,43}, p<0.001$ ). Enriched WT mice similarly demonstrated intact recall of platform location (Figure 2c; WTEE: $\mathrm{F}_{3,34}=16.21, p<0.001$ ). While the majority of SH WT mice show a 2-fold preference for the target quadrant compared with other quadrants, this was not significant due to two mice switching search strategies to adjacent quadrants immediately after searching in the target. Deficits in probe trial performance were not due to impaired movement as there was no significant difference in distance covered during the probe trial between groups (Supplementary Figure 1a) or their ability to find a visible platform (Supplementary Figure 1b). The lack of preference for the platform quadrant in SH WT mice makes it difficult to draw clear conclusions on the effect of EE on memory recall in $\mathrm{KO}$ mice. Nevertheless, EE reduced AUC latencies in KO mice during the acquisition period of the MWM, reflecting a beneficial effect on learning in $\mathrm{KO}$ mice. In the $\mathrm{Y}$-maze, $\mathrm{KO}$

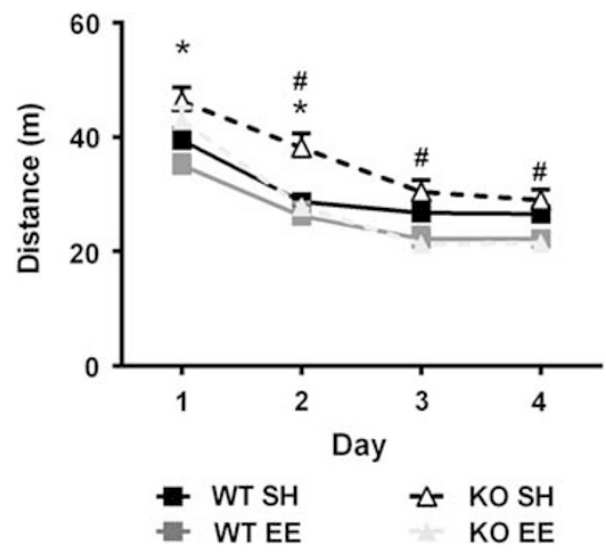

Figure I Total 15 min locomotor activity levels in photo-beam arenas over 4 consecutive days. KO mice exhibit hyperactivity on days I and 2 . Environmental enrichment lowered activity levels in both $\mathrm{KO}$ and WT. Data expressed as mean \pm SEM; * $p<0.05$ genotype, ${ }^{\#} p<0.05$ environment.

mice show impaired short-term memory, showing reduced preference for the novel arm compared with WT mice (Figure 2d; genotype: $\mathrm{F}_{1,34}=9.52, p<0.01$ ). Exposure to $\mathrm{EE}$ did not alter novelty preference in $\mathrm{Y}$-maze however did decrease distance covered by mice (Supplementary Figure 1c; environment: $F_{1,34}=7.23, p<0.01$ ). No differences were seen between WT and KO mice in the light-dark box or elevated plus maze, indicating that anxiety did not confound performance in the Y-maze (Supplementary Figure 1d and e).

\section{EE Ameliorates the PPI Deficit in mGlu5 KO Mice and Reduces Startle}

A significant PPI deficit was observed in $\mathrm{KO}$ mice compared with their WT littermates (main effect of genotype: $\left.\mathrm{F}_{1,137}=17.96, p<0.001\right)$ and this effect was more prominent at the $30 \mathrm{~ms}$ ISI (ISI $\times$ genotype interaction $\mathrm{F}_{1,137}=21.28$, $p<0.001$; main effect of ISI: $\mathrm{F}_{1,137}=12.62, p<0.001$ ). At the 30-ms ISI, EE normalizes the PPI deficit in saline-injected mGlu5 KO mice (Figure 3a; gene $\times$ environment interaction: $\mathrm{F}_{1,48}=7.73, p=0.008$, KOSH $v$ KOEE $p=0.048$; main effect of genotype: $\mathrm{F}_{1,48}=11.061, p<0.01$ ) but it had no effect in WT mice. There was no significant effect of genotype or EE or interaction at the 100-ms ISI (Supplementary Figure 2).

Mice showed comparable startle habituation across the testing period (data not shown; main effect of pulse block: $\left.\mathrm{F}_{3,411}=37.89, p<0.001\right)$. The mGlu5 $\mathrm{KO}$ mice showed lower startle responses compared with WT controls (Figure 3b; genotype: $\left.\mathrm{F}_{1,137}=11.88, p<0.001\right)$ and environmental enrichment reduced startle magnitude (environment: $\left.\mathrm{F}_{1,137}=9.36, p<0.01\right)$ but there was no differential effect of $\mathrm{EE}$ between genotypes.

\section{Effects of EE on Hippocampal BDNF Protein Levels, NMDA Receptor Composition and Dendritic Branch Complexity in mGlu5 KO Mice}

Hippocampal BDNF protein levels were increased following $\mathrm{EE}$ in WT mice, but not in $\mathrm{KO}$ mice (Supplementary Figure 3; gene $\times$ environment interaction: $\mathrm{F}_{1,34}=4.40$; $p<0.05$, WTEE vs KOEE, $p<0.001)$. Furthermore, EE modulated NMDA receptor subunit composition in the 

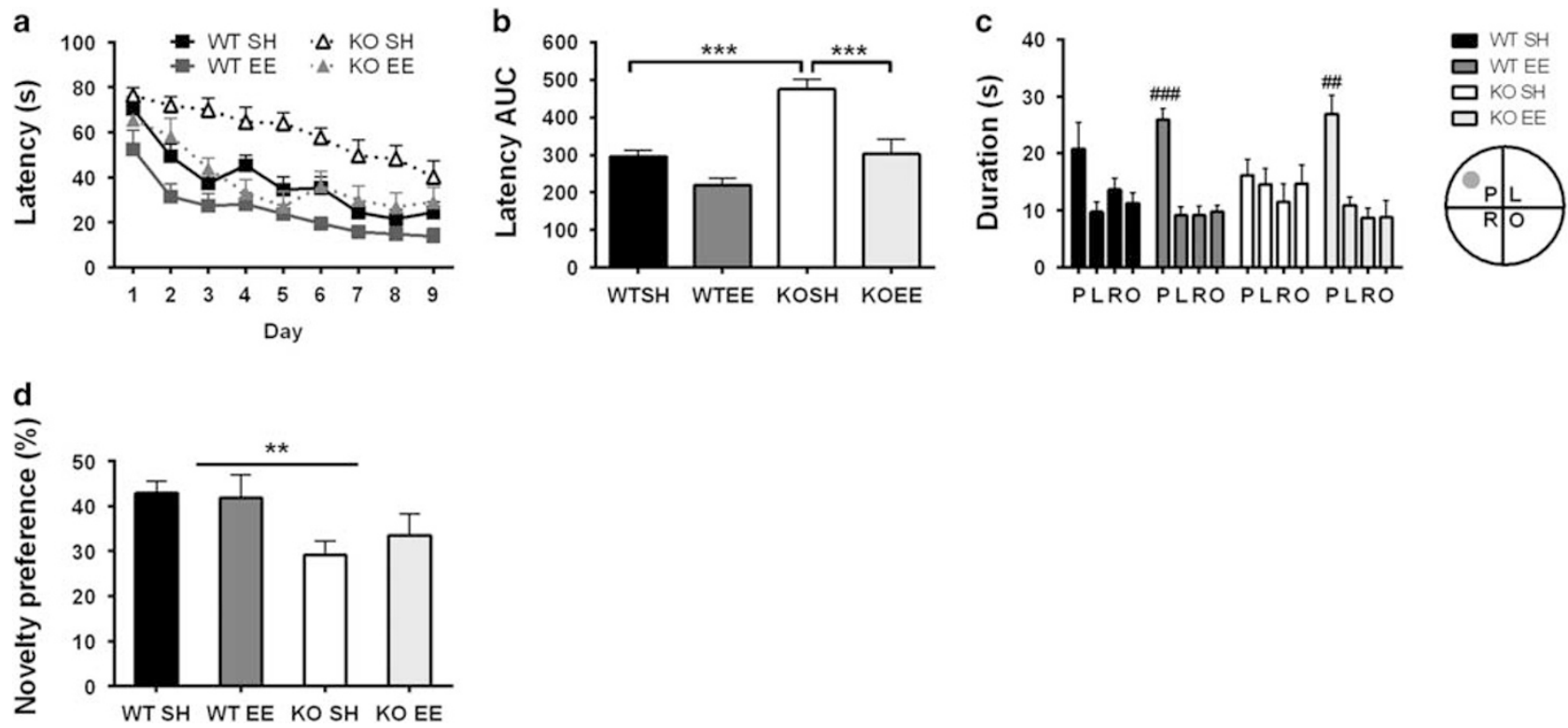

Figure 2 (a) Mice were assessed for learning in the MWM over a period of 9 days. (b) Standard-housed KO mice were impaired in their ability to locate the escape platform compared with WT controls, as reflected in latency area under the 9-day learning curve (AUC). Improvement in learning in KO mice was seen following exposure to environmental enrichment. (c) Mice were tested for their recall of the platform location on the IOth day. Standard-housed KO mice failed to show a preference for the platform quadrant. Enrichment improved recall of the platform position in both $\mathrm{KO}$ and WT mice. (d) In the $\mathrm{Y}$ maze, $\mathrm{KO}$ mice spent less time in the novel arm vs other arms compared with WT mice, indicating that they do not recognize the novel arm. Data are expressed as mean \pm SEM; $n=8-13$ per group; ${ }^{* *} p<0.01{ }^{* * * *} p<0.001$, \#\# $p<0.01{ }^{\# \# \#} p<0.001$ quadrant.
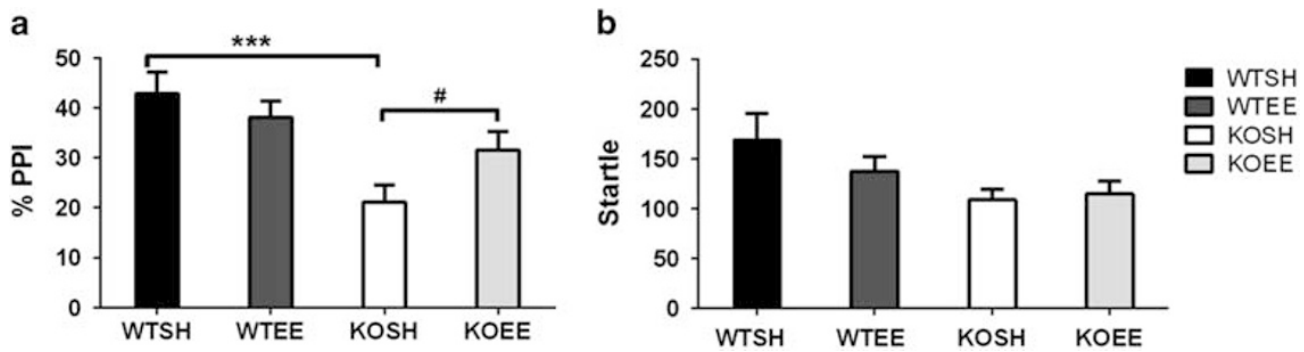

Figure 3 (a) mGlu5 $\mathrm{KO}$ mice show disrupted PPI and environmental enrichment normalizes this deficit. (b) $\mathrm{KO}$ mice showed lower startle responses compared with WT controls and environmental enrichment reduced startle magnitude in both genotypes. Data are average \%PPI (2, 4, 8, I6 dB prepulse intensities) and is expressed as mean \pm SEM; ${ }^{* * * *} p<0.00$ I genotype, ${ }^{\#} p<0.05$ gene $\times$ environment interaction.

hippocampus. EE significantly increased levels of GluN2A (Supplementary Figure 4a; environment: $\mathrm{F}_{1,22}=5.88$, $p<0.05)$ and this effect was not different between WT and KO mice. Neither environment nor genotype significantly influenced GluN2B or GluN1 subunit expression (Supplementary Figure $4 \mathrm{~b}$ ).

Golgi-impregnated CA1 pyramidal neurons of SH WT and $\mathrm{KO}$ mice displayed similar dendritic morphology. Increased dendritic branching was evident in WT mice housed in enriched environments; however, KO mice were resistant to this experience-dependent plasticity (Supplementary Figure 5a; gene $\times$ environment $\times$ length interaction: $\mathrm{F}_{14,2133}$ $=1.69, p<0.05$, WTEE $v s$ KOEE, $p<0.05 ; 40 \mu \mathrm{m} p=0.044$; $50 \mu \mathrm{m} p=0.017)$. In contrast to dendritic length, quantitative analysis of dendritic-spine density on CA1 pyramidal cells revealed no significant difference between WT mice and KO mice (Supplementary Figure 5b).

\section{EE Modulates Behavioral Response to the NMDA Receptor Antagonist MK-801 in mGlu5 KO Mice}

No differences in locomotor activity levels were seen between genotypes or differentially housed mice during habituation (Figure $4 \mathrm{a}$ and c: -30 to $0 \mathrm{~min}$ ). After MK-801 treatment, mGlu5 KO mice displayed a different pattern of activity in response to MK-801 administration compared with WT (genotype $\times$ dose interaction for data from 0 to $60 \mathrm{~min}$ : $\left.\mathrm{F}_{2,57}=6.40, p<0.01\right)$. WT mice were only hyperactive in response to $0.25 \mathrm{mg} / \mathrm{kg}$ MK-801 (Figure 4a; time $\times$ dose interaction for WT only: $\left.F_{26,351}=14.06, p<0.001\right)$. EE did not alter WT response to MK-801 (Figure 4a and b). In contrast, KO mice were hyperactive at both 0.15 and $0.25 \mathrm{mg} / \mathrm{kg}$ doses (Figure $4 \mathrm{c}$ and $\mathrm{d}$; time $\times$ dose interaction for KO only: $\left.\mathrm{F}_{24,396}=12.41, p<0.001\right)$. The hyperlocomotive effects in $\mathrm{KO}$ mice were further increased by $\mathrm{EE}$ and 
a

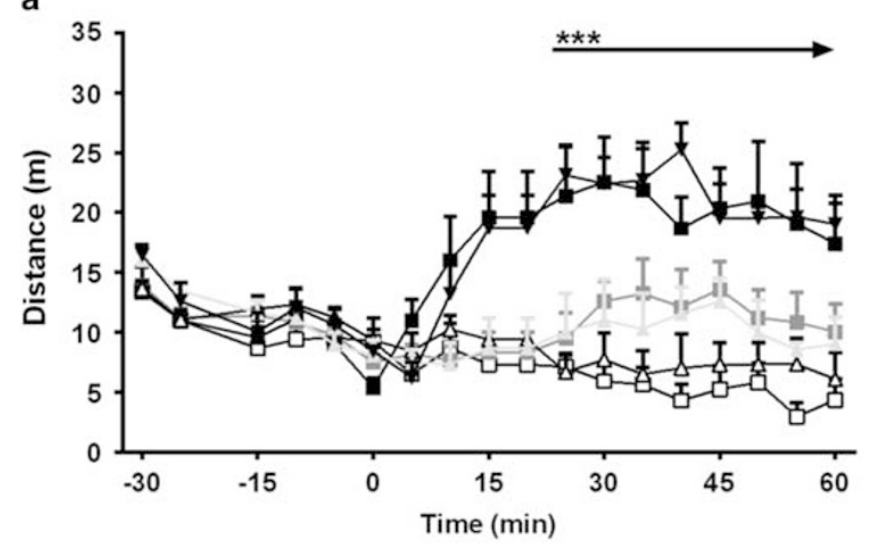

c

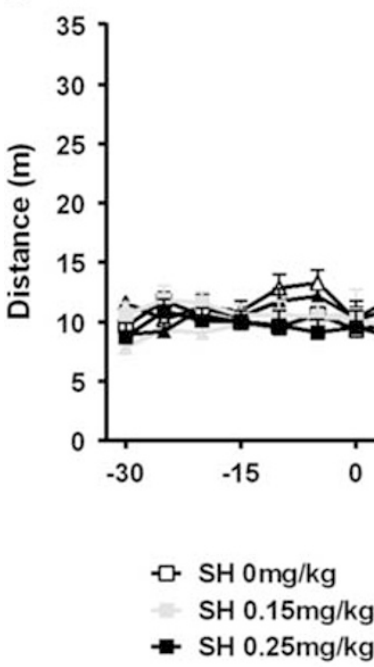

Time (min)
\#曹

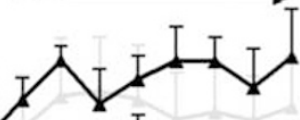

\#
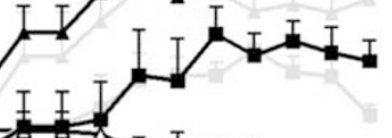

工
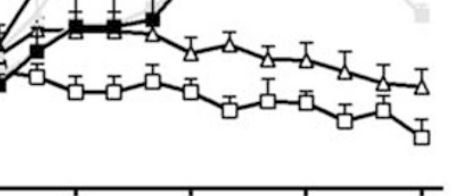

0

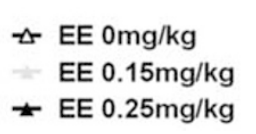

b

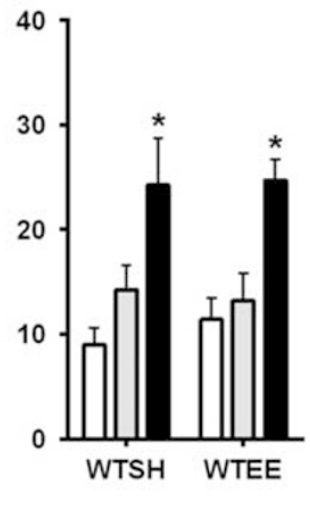

d

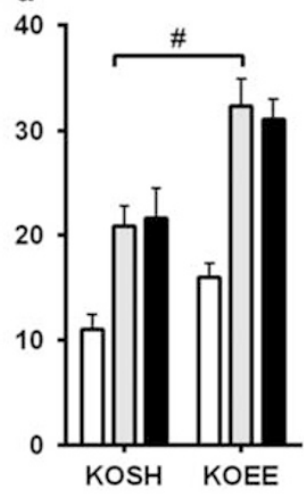

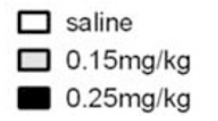

Figure 4 (a) Activity levels were monitored in photo-beam arenas for $30 \mathrm{~min}$ and at time 0 , mice were injected with Saline or MK-80 I at 0.15 or $0.25 \mathrm{mg} /$ kg. (a, b) WT mice exhibited MK-80I induced hyperactivity at the $0.25-\mathrm{mg} / \mathrm{kg}$ dose only and environmental enrichment had no effect on the response to the antagonist. (c, d) $\mathrm{KO}$ mice exhibited hyperactivity in response to MK-80I treatment at both doses and environmental enrichment further increased this hyperactivity. Data expressed as mean \pm SEM; $n=5-7$ per group; ${ }^{*} p<0.05$, ${ }^{*} p<<0.0$ l, ${ }^{*} * * *<0.00 \mathrm{l}$. Saline vs $0.25 \mathrm{mg} / \mathrm{kg}$ dose, ${ }^{\#} p<0.05,{ }^{\# \#} p<0.00$ I; Saline vs $0.15 \mathrm{mg} / \mathrm{kg}$, arrow denotes continuous significant data points.
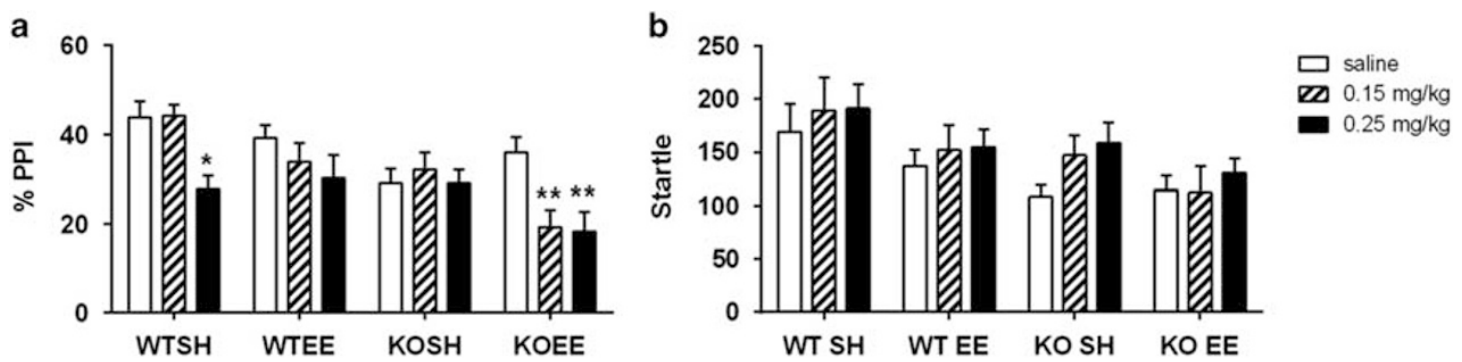

Figure 5 (a) $\mathrm{KO}$ mice show a resistance to $\mathrm{MK}-80 \mathrm{I}$-induced PPI disruptions. Environmental enrichment reinstated the normal response and increased sensitivity to MK-80 I in KO mice. (b) MK-80 I did not alter startle amplitude in WT or KO mice. Data expressed as mean \pm SEM of 9-15 mice per group; * $p<0.05$, *** $p<0.0$ I (genotype).

enriched KO mice showed a greater degree of hyperactivity in response to the $0.15-\mathrm{mg} / \mathrm{kg}$ dose of MK-801 than standard-housed $\mathrm{KO}$ (Figure 4d; genotype $\times$ environment $\times$ dose interaction: $\mathrm{F}_{2,92}=6.09, p<0.01 \mathrm{KOSH} v s$ KOEE saline $p<0.05$ for $0.15 \mathrm{mg} / \mathrm{kg}$ dose only).

Exposure to EE differentially modulated the PPI response to MK-801 treatment between genotypes at the $30-\mathrm{ms}$ ISI (Figure 5a; gene $\times$ environment $\times$ dose interaction for $30 \mathrm{~ms}$
ISI data only: $\left.\mathrm{F}_{2,88}=3.17, p<0.05\right)$. No gene or environment effects were seen at $100 \mathrm{~ms}$ ISI. WT mice housed under standard conditions showed significant disruption in PPI when treated with $0.25 \mathrm{mg} / \mathrm{kg}$ MK-801 but not with $0.15 \mathrm{mg} / \mathrm{kg}$ MK-801 (Figure 5a; Saline $v s 0.25 \mathrm{mg} / \mathrm{kg} p<0.05$, 0.15 vs $0.25 \mathrm{mg} / \mathrm{kg} p<0.01)$. Enriched WT mice showed no significant disruption in PPI following MK-801 treatment. SH KO mice did not show MK-801-induced 
disruptions in PPI when treated with either dose compared with saline treatment. Exposing $\mathrm{KO}$ mice to environmental enrichment reinstated a normal MK-801-induced PPI disruption (Figure 5a). Like SH WT, EE KO mice showed a significant impairment in PPI when treated with $0.25 \mathrm{mg} /$ $\mathrm{kg}$ MK-801, however also with the lower $0.15 \mathrm{mg} / \mathrm{kg}$ dose, indicating a heightened sensitivity to MK-801 (Saline vs $0.15 \mathrm{mg} / \mathrm{kg} p<0.01$ and Saline $v s 0.25 \mathrm{mg} / \mathrm{kg} p<0.01$ ). Startle was unaffected by MK-801 treatment; however, a trend indicated a slight increase in startle magnitude (Figure 5b; dose: $\mathrm{F}_{2,136}=2.85, p=0.061$ ).

\section{DISCUSSION}

The present study demonstrates the influence of environmental factors on the regulation of mGlu5-dependent schizophrenia behavioral impairments. We show that environmental enrichment ameliorates PPI and long-term spatial learning deficits and reduces spontaneous hyperactivity in mGlu5 KO mice. Mutant mice exposed to environmental enrichment showed altered behavioral responses to the NMDAR antagonist MK-801, indicating that this manipulation can influence NMDA receptor function.

Our study confirms previous findings of disrupted PPI and locomotor hyperactivity in mGlu5 KO mice (Brody et al, 2004; Gray et al, 2009). We extend upon this, showing that these behavioral phenotypes are restored by environmental enrichment. PPI disruption and locomotor hyperactivity in mGlu5 KO mice have also been shown to be normalized by chronic administration of clozapine, accompanied by an increase in NMDAR binding (Gray et al, 2009). Enhancement of glutamatergic signaling via the NMDAR glycine site and the AMPA receptor similarly ameliorates PPI in mGlu5 KO mice (Lipina et al, 2007; Chen et al, 2010). Here we show that environmental enrichment also ameliorates PPI, potentially drawing a parallel between the therapeutic effects of a positive environment and pharmacological treatment. Consistent with previous reports, cognitive impairments in mGlu5 KO mice were identified in hippocampal-dependent tasks assessing both long-term and short-term spatial learning and memory (Lu et al, 1997; Gray et al, 2009). A corrective effect of environmental enrichment was seen on long-term spatial learning impairment in mGlu5 KO mice. The lack of environmental modulation of short-term memory implies that this form of memory is resistant to enrichment-induced improvement, under these conditions. BDNF levels and CA1 pyramidal cell dendritic complexity and spine density were investigated as potential correlates of impaired memory, and while these could not explain the enrichment-induced improvements, we were nonetheless able to conclude that mGlu5 is critical to the experiencedependent effects of a positive environment on hippocampal BDNF or cell morphology. Increased expression of BDNF in the hippocampus has been associated with enrichmentinduced improvements in spatial memory (Falkenberg et al, 1992; Pham et al, 2002). Consistent with these reports, EE increased BDNF protein levels in WT mice. However, no improvement in learning or memory was observed in EE WT mice, potentially due to the degree of difficulty of the tasks used and ceiling effects in performance. EE has been shown to have notable effects on structural plasticity in WT animals, including increasing dendritic branching and length, number of dendritic spines, and size of synapses (Faherty et al, 2003; Greenough and Volkmar, 1973; Leggio et al, 2005). In the present study, WT animals raised in environmentally enriched conditions show subtle alterations in dendritic complexity; however, spine density was unchanged. Similarly, Nithianantharajah et al, (2009), utilizing a similar enrichment paradigm to the one in this study, also showed no effect of enrichment rearing on spine number in the CA1 region. Many of the reported effects on structural plasticity following enrichment are from studies utilizing rats, a considerably different model from mice. Furthermore, differences between the present study and others in the literature may be in part due to the variability in enrichment paradigms. Environmental enrichment did not induce any structural changes in mGlu5 $\mathrm{KO}$ mice. Given the role of mGlu5 in experience-dependent development and plasticity, in particular in visual and somatosensory cortex (Hannan et al, 2001; Wijetunge et al, 2008), the absence of structural plasticity in the hippocampus in response to an enriched environment in mGlu5 $\mathrm{KO}$ mice is not surprising. While disrupted experience-dependent plasticity could account for the learning and memory impairments in mGlu5 $\mathrm{KO}$ mice, it cannot explain the enrichment-induced improvements in behavior. It is important to note the possibility that there may have been wider changes due to enrichment that were transient and not detected after the extended exposure to the paradigm. For example, dendritic spines are highly dynamic and the analysis in the present study is only representative of a single snapshot in time. Furthermore, only one population of neurons was sampled, so changes in morphological plasticity elsewhere cannot be ruled out.

The absence of mGlu5 causes dysregulation of NMDAR signaling, as evidenced by altered responses to MK-801 in mGlu5 KO mice. Doses of MK-801 that were sub-threshold in WT animals produced a robust locomotor response in the mGlu5 KO mice. While the mechanisms through which NMDAR antagonists induce hyperlocomotion are far from being elucidated, the observed sensitivity to the effects of MK-801 in mGlu5 KO mice is in direct agreement with the ability of mGlu5 antagonists to potentiate MK-801-induced hyperlocomotion (Pietraszek et al, 2005). The synergistic action of mGlu5 ablation and MK-801 suggests that mGlu5 has a modulatory role in the effects of NMDAR antagonists. Following enrichment, the response to MK-801 in mGlu5 $\mathrm{KO}$ mice was potentiated, with $\mathrm{KO}$ mice showing significantly higher levels of hyperactivity compared with $\mathrm{KO}$ mice housed in standard conditions. In agreement with the previous finding, the current work demonstrated impaired PPI in mGlu5 KO mice to a level that was not disrupted further by MK-801 (Lipina et al, 2007). This is unlikely to be a 'floor' effect caused by reduced baseline levels of PPI in mGlu5 KO mice, as it has been shown that higher doses of MK-801 than those used in the present study can elicit further disruptions in PPI in mGlu5 KO mice compared with saline controls, suggesting that $\mathrm{KO}$ mice show a reduced sensitivity to the drug rather than a complete resistance (Lipina et al, 2007). Thus, the present results cannot be explained simply by altered baseline PPI in standard-housed or environmentally-enriched $\mathrm{KO}$ mice. Exposure to enrichment reinstated a normal MK-801-induced PPI disruption in mGlu5 KO mice. This increase in sensitivity to MK-801- 
mediated disruption in PPI may be attributed to restoration of NMDAR function.

Alterations in NMDAR composition and/or activity could account for the increased sensitivity to MK-801-induced hyperlocomotion noted in mGlu5 $\mathrm{KO}$ mice, given the functional and physical links between the two receptors. It has been shown that while NMDAR expression in mGlu5 KO mice is similar to controls (Gray et al, 2009), a complete loss of the NMDAR-dependent component of hippocampal LTP is evident in the same KO line, suggesting significantly impacted receptor function (Jia et al, 1998). NMDAR exists as multiple subtypes with distinct pharmacological and biophysical properties that are largely determined by the type of GluN2 subunit (GluN2A to GluN2D) incorporated in the heteromeric GluN1/GluNR2 complex (Dingledine et al, 1999; Cull-Candy and Leszkiewicz, 2004; Paoletti and Neyton, 2007; Gielen et al, 2009). A study in adult mGlu5 KO mice established that mGlu5 and NMDARs are required for the activity-dependent GluN2B-GluN2A switch, and have a critical role in experience-dependent regulation of NMDAR subunit composition in vivo (Matta et al, 2011). While we do not report significant alterations in total NMDAR (GluN1), GluN2A or GluN2B protein levels in mGlu5 KO mice compared with WT controls this could be due to subtle regional or cell specific differences in subunit expression. Nonetheless we did detect an enrichmentinduced increase in GluN2A subunit levels that was not significantly different between WT and KO mice, suggesting that beneficial effects of EE may at least partly be the result of increased GluN2A-containing NMDARs.

Enrichment differentially modulated the behavioral response to MK-801 in mGlu5 KO mice compared with WT mice. Consistent with a role for GluN2A in the behavioral responses observed, MK-801 has been shown to have much higher affinity for GluN2A-containing NMDARs and thus, an increase in GluN2A-containing NMDARs could explain the increased sensitivity to MK-801 seen following EE (Laurie and Seeburg, 1994; Gielen et al, 2009). Furthermore, several lines of evidence support the essential role of GluN2A-containing receptors in LTP, thus it is feasible that in the present study, enrichment improved learning in mGlu5 KO mice by enhancing LTP (Kochlamazashvili et al, 2012; Volianskis et al, 2013). Further examination of functional properties of NMDAR in mGlu5 $\mathrm{KO}$ mice following enrichment is warranted to confirm this.

The findings presented in this study contribute to a growing literature investigating the biochemical mechanisms that underlie the impact of positive environmental stimulation on neural function. To date, EE has been shown to upregulate the expression of other NMDAR subunits and additional components of the glutamatergic system, signifying that restoration of NMDAR dysfunction either directly through NMDARs or through enhancing glutamatergic signaling may be a critical component in the beneficial effects of EE on behavior (Tang et al, 2001; Bredy et al, 2003; Naka et al, 2005; Andin et al, 2007; Mora et al, 2007; Sun et al, 2010).

In summary, the present results provide several conclusions. Lack of mGlu5 in null mutant mice causes impairments in behavioral modalities-PPI, locomotor activity, spatial learning and memory-which are relevant to schizophrenia. The behavioral phenotype was susceptible to environmental modulation, giving this animal model validity in modeling gene-environment interactions in psychiatric illness. The absence of mGlu5 causes dysregulation of the NMDAR, as evidenced by the responses to MK- 801 observed in KO mice, supporting the link between the mGlu5 and NMDAR. Environmental enrichment exacerbated responses to MK-801, suggesting that the beneficial effects of this paradigm on behavior are due to modifications in NMDAR signaling. This series of experiments has afforded greater insight into the role of mGlu5 in schizophrenia-related behavioral impairments. Furthermore, it supports the involvement of NMDAR in the beneficial effects of enrichment. The idea that environmental interventions could protect against the effects of genetic vulnerabilities offers avenues toward the elaboration and refinement of therapeutic strategies. Furthermore, given that compounds that enhance glutamatergic signaling are receiving much interest in the treatment of schizophrenia, a greater understanding of how mGlu5 can modulate NMDAR activity and regulate schizophrenia-related endophenotypes is of significant therapeutic importance.

\section{FUNDING AND DISCLOSURE}

The authors declare no conflict of interest.

\section{ACKNOWLEDGMENTS}

We thank past and present laboratory members for useful discussions. Thank you to Maria Bastias, Daniel Drieberg, Ana Hudson, Maddison Lee Ible, Sally Martin, Brett Purcell, and Craig Thomson for their technical assistance. This work was funded by National Health Medical Research Council (NHMRC) project grant (APP1034785) to AJH. AJH has been supported by an Australian Research Council (ARC) FT3 Future Fellowship (FT100100835) and an NHMRC Senior Research Fellowship. CEM is supported by a NHMRC CJ Martin Overseas Biomedical Fellowship, and a Brain and Behavior Research Foundation Young Investigator Award. MvdB is supported by an NHMRC Senior Research Fellowship.

\section{REFERENCES}

Adler CM, Malhotra AK, Elman I, Goldberg T, Egan M, Pickar D et al (1999). Comparison of ketamine-induced thought disorder in healthy volunteers and thought disorder in schizophrenia. Am J Psychiatry 156: 1646-1649.

Andin J, Hallbeck M, Mohammed AH, Marcusson J (2007). Influence of environmental enrichment on steady-state mRNA levels for EAAC1, AMPA1 and NMDA2A receptor subunits in rat hippocampus. Brain Res 1174: 18-27.

Bredy TW, Humpartzoomian RA, Cain DP, Meaney MJ (2003). Partial reversal of the effect of maternal care on cognitive function through environmental enrichment. Neuroscience 118: 571-576.

Brenes JC, Rodriguez O, Fornaguera J (2008). Differential effect of environment enrichment and social isolation on depressive-like behavior, spontaneous activity and serotonin and norepinephrine concentration in prefrontal cortex and ventral striatum. Pharmacol Biochem Behav 89: 85-93.

Brody SA, Dulawa SC, Conquet F, Geyer MA (2004). Assessment of a prepulse inhibition deficit in a mutant mouse lacking mGlu5 receptors. Mol Psychiatry 9: 35-41. 
Brody SA, Geyer MA (2004). Interactions of the mGluR5 gene with breeding and maternal factors on startle and prepulse inhibition in mice. Neurotox Res 6: 79-90.

Burrows EL, McOmish CE, Hannan AJ (2011). Gene-environment interactions and construct validity in preclinical models of psychiatric disorders. Prog Neuropsychopharmacol Biol Psychiatry 35: $1376-1382$.

Campbell UC, Lalwani K, Hernandez L, Kinney GG, Conn PJ, Bristow LJ (2004). The mGluR5 antagonist 2-methyl-6-(phenylethynyl)-pyridine (MPEP) potentiates PCP-induced cognitive deficits in rats. Psychopharmacology (Berl) 175: 310-318.

Chen HH, Stoker A, Markou A (2010). The glutamatergic compounds sarcosine and $\mathrm{N}$-acetylcysteine amerliorate prepulse inhibition deficits in metabotropic glutamate 5 recptor knockout mice. Psychopharmacology (Berl) 209: 343-350.

Chourbaji S, Brandwein C, Vogt MA, Dormann C, Hellweg R, Gass P (2008). Nature vs. nurture: can enrichment rescue the behavioural phenotype of BDNF heterozygous mice? Behav Brain Res 192: 254-258.

Cull-Candy SG, Leszkiewicz DN (2004). Role of distinct NMDA receptor subtypes at central synapses. Sci STKE 255: re16.

Devon RS, Anderson S, Teague PW, Muir WJ, Murray V, Pelosi AJ et al (2001). The genomic organisation of the metabotropic glutamate receptor subtype 5 gene, and its association with schizophrenia. Mol Psychiatry 6: 311-314.

Dingledine R, Borges K, Bowie D, Traynelis SF (1999). The glutamate receptor ion channels. Pharmacol Rev 51: 7-61.

Faherty CJ, Kerley D, Smeyne RJ (2003). A Golgi-Cox morphological analysis of neuronal changes induced by environmental enrichment. Brain Res Dev Brain Res 141: 55-61.

Falkenberg T, Mohammed AK, Henriksson B, Persson $\mathrm{H}$, Winblad B, Lindefors N (1992). Increased expression of brainderived neurotrophic factor mRNA in rat hippocampus is associated with improved spatial memory and enriched environment. Neurosci Lett 138: 153-156.

Fradley RL, O'Meara GF, Newman RJ, Andrieux A, Job D, Reynolds DS (2005). STOP knockout and NMDA NR1 hypomorphic mice exhibit deficits in sensorimotor gating. Behav Brain Res 163: 257-264.

Gielen M, Siegler B, Retchless L, Mony J, Johnson W, Paoletti P (2009). Mechanism of differential control of NMDA receptor activity by NR2 subunits. Nature 459: 703-707.

Gray L, Hannan AJ (2007). Dissecting cause and effect in the pathogenesis of psychiatric disorders: genes, environment and behaviour. Curr Mol Med 7: 470-478.

Gray L, van den Buuse M, Scarr E, Dean B, Hannan AJ (2009). Clozapine reverses schizophrenia-related behaviours in the metabotropic glutamate receptor 5 knockout mouse: association with $\mathrm{N}$-methyl-D-aspartic acid receptor up-regulation. Int $J$ Neuropsychopharmacol 12: 45-60.

Greenough WT, Volkmar FR (1973). Pattern of dendritic branching in occipital cortex of rats reared in complex environments. Exp Neurol 40: 491-504.

Gupta DS, McCullumsmith RE, Beneyto M, Haroutunian V, Davis KL, Meador-Woodruff JH (2005). Metabotropic glutamate receptor protein expression in the prefrontal cortex and striatum in schizophrenia. Synapse 57: 123-131.

Hannan AJ, Blakemore C, Katsnelson A, Vitalis T, Huber KM, Bear M, Roder J, Kim D, Shin HS, Kind PC (2001). PLC- $\beta 1$, activated via mGluRs, mediates activity-dependent differentiation in cerebral cortex. Nat Neurosci 4: 282-288.

Henry SA, Lehmann-Masten V, Gasparini F, Geyer MA, Markou A (2002). The mGluR5 antagonist MPEP, but not the mGluR2/3 agonist LY314582, augments PCP effects on prepulse inhibition and locomotor activity. Neuropharmacology 43: 1199-1209.

Jia Z, Lu Y, Henderson J, Taverna F, Romano C, Abramow-Newerly W et al (1998). Selective abolition of the NMDA component of long-term potentiation in mice lacking mGluR5. Learn Mem 5: 331-343.

Kinney GG, Burno M, Campbell UC, Hernandez LM, Rodriguez D, Bristow LJ et al (2003). Metabotropic glutamate subtype 5 receptors modulate locomotor activity and sensorimotor gating in rodents. J Pharmacol Exp Ther 306: 116-123.

Kochlamazashvili G, Bukalo O, Senkov O, Salmen B, GerardySchahn R, Engel AK et al (2012). Restoration of synaptic plasticity and learning in young and aged NCAM-deficient mice by enhancing neurotransmission mediated by GluN2A-containing NMDA receptors. J Neurosci 32: 2263-2275.

Krystal JH, Karper LP, Seibyl JP, Freeman GK, Delaney R, Bremner JD et al (1994). Subanesthetic effects of the noncompetitive NMDA antagonist, ketamine, in humans. Psychotomimetic, perceptual, cognitive, and neuroendocrine responses. Arch Gen Psychiatry 51: 199-214.

Laurie DJ, Seeburg PH (1994). Ligand affinities at recombinant $\mathrm{N}$-methyl-D-aspartate receptors depend on subunit composition. Eur J Pharmacol 268: 335-345.

Leggio MG, Mandolesi L, Federico F, Spirito F, Ricci Bl, Gelfo F, Petrosini L (2005). Environmental enrichment promotes improved spatial abilities and enhanced dendritic growth in the rat. Behav Brain Res 163: 78-90.

Lipina T, Weiss K, Roder J (2007). The ampakine CX546 restores the prepulse inhibition and latent inhibition deficits in mGluR5-deficient mice. Neuropsychopharmacology 32: 745-756.

Lu YM, Jia Z, Janus C, Henderson JT, Gerlai R, Wojtowicz JM et al (1997). Mice lacking metabotropic glutamate receptor 5 show impaired learning and reduced CA1 long-term potentiation (LTP) but normal CA3 LTP. J Neurosci 17: 5196-5205.

Matta JA, Ashby MC, Sanz-Clemente A, Roche KW, Isaac JT (2011). mGluR5 and NMDA receptors drive the experience- and activity-dependent NMDA receptor NR2B to NR2A subunit switch. Neuron 70: 339-351.

McOmish CE, Burrows E, Howard M, Scarr E, Kim D, Shin HS et al (2008). Phospholipase C-beta1 knockout mice exhibit endophenotypes modeling schizophrenia which are rescued by environmental enrichment and clozapine administration. Mol Psychiatry 13: $661-672$.

Meador-Woodruff JH, Healy DJ (2000). Glutamate receptor expression in schizophrenic brain. Brain Res Brain Res Rev 31: 288-294.

Mirnics K, Middleton FA, Marquez A, Lewis DA, Levitt P (2000). Molecular characterization of schizophrenia viewed by microarray analysis of gene expression in prefrontal cortex. Neuron 28: 53-67.

Mohn AR, Gainetdinov RR, Caron MG, Koller BH (1999). Mice with reduced NMDA receptor expression display behaviors related to schizophrenia. Cell 98: 427-436.

Mora F, Segovia G, del Arco A (2007). Aging, plasticity and environmental enrichment: structural changes and neurotransmitter dynamics in several areas of the brain. Brain Res Rev 55: 78-88.

Naka F, Narita N, Okado N, Narita M (2005). Modification of AMPA receptor properties following environmental enrichment. Brain Dev 27: 275-278.

Nithianantharajah J, Hannan AJ (2006). Enriched environments, experience-dependent plasticity and disorders of the nervous system. Nat Rev Neurosci 7: 697-709.

Nithianantharajah J, Barkus C, Vijiaratnam N, Clement O, Hannan AJ (2009). Modeling brain reserve: experiencedependent neuronal plasticity in healthy and Huntington's disease transgenic mice. Am J Geriatr Psychiatry 17: 196-209.

Paoletti P, Neyton J (2007). NMDA receptor subunits: function and pharmacology. Curr Opin Pharmacol 7: 39-47.

Paxinos G, Franklin KBJ (2001). The Mouse Brain in Stereotaxic Coordinates, 2nd edn. Academic Press: San Diego, CA. 
Pham TM, Winblad B, Granholm AC, Mohammed AH (2002). Environmental influences on brain neurotrophins in rats. Pharmacol Biochem Behav 73: 167-175.

Pietraszek M, Gravius A, Schafer D, Weil T, Trifanova D, Danysz W (2005). mGluR5, but not mGluR1, antagonist modifies MK-801induced locomotor activity and deficit of prepulse inhibition. Neuropharmacology 49: 73-85.

Rodrigues SM, Bauer EP, Farb CR, Schafe GE, LeDoux JE (2002). The group I metabotropic glutamate receptor mGluR5 is required for fear memory formation and long-term potentiation in the lateral amygdala. J Neurosci 22: 5219-5229.

Sholl DA (1953). Dendritic organization in the neurons of the visual and motor cortices of the cat. J Anat 87: 387-406.

Sun H, Zhang J, Zhang L, Liu H, Zhu H, Yang Y (2010). Environmental enrichment influences BDNF and NR1 levels in the hippocampus and restores cognitive impairment in chronic cerebral hypoperfused rats. Curr Neurovasc Res 7: 268-280.

Tang YP, Wang H, Feng R, Kyin M, Tsien JZ (2001). Differential effects of enrichment on learning and memory function in NR2B transgenic mice. Neuropharmacology 41: 779-790.

Terry AV, Mahadik SP (2007). Time-dependent cognitive deficits associated with first and second generation antipsychotics: cholinergic dysregulation as a potential mechanism.J Pharmacol Exp Ther 320: 961-968.

Tsien JZ, Huerta PT, Tonegawa S (1996). The essential role of hippocampal CA1 NMDA receptor-dependent synaptic plasticity in spatial memory. Cell 87: 1327-1338.
Tu JC, Xiao B, Naisbitt S, Yuan JP, Petralia RS, Brakeman P et al (1999). Coupling of mGluR/Homer and PSD-95 complexes by the Shank family of postsynaptic density proteins. Neuron 23: 583-592.

van den Buuse $M$, Martin S, Brosda J, Leck KJ, Matthaei KI, Hendry I (2005). Enhanced effect of dopaminergic stimulation on prepulse inhibition in mice deficient in the alpha subunit of $\mathrm{G}(\mathrm{z})$. Psychopharmacology (Berl) 183: 358-367.

van den Buuse M, Becker T, Kwek P, Martin S, Ruimschotel E, Risbrough V (2011). Disruption of prepulse inhbition by 3, 4-methylenedioxymethampthetamine (MDMA): comparison between male and female wild-type and 5-HT(1A) receptor knockout mice. Int J Neuropsychopharmacol 14: 856-861.

van Elst LT, Valerius $G$, Buchert $M$, Thiel T, Rusch N, Bubl E et al (2005). Increased prefrontal and hippocampal glutamate concentration in schizophrenia: evidence from a magnetic resonance spectroscopy study. Biol Psychiatry 58: 724-730.

Volianskis A, Collingridge GL, Jensen MS (2013). The roles of STP and LTP in synaptic encoding. Peer J 1: e3.

Wijetunge LS, Till SM, Gillingwater $\mathrm{TH}$, Ingham CA, Kind PC (2008). mGluR5 regulates glutamate-dependent development of the mouse somatosensory cortex. I Neurosci 28: 13028-13037.

Youngblood BD, Zhou J, Smagin GN, Ryan DH, Harris RB (1997). Sleep deprivation by the 'flower pot' technique and spatial reference memory. Physiol Behav 61: 249-256.

Supplementary Information accompanies the paper on the Neuropsychopharmacology website (http://www.nature.com/npp) 